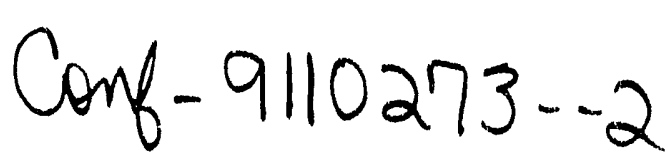

WSRC-MS--91-276

DE92 009442

\title{
UPGRADE OF THE DEPARTMENT OF ENERGY'S SA VANNAH RIVER SITE'S REACTOR OPERATIONS AND MAINTENANCE PROCEDURES (U)
}

by

T. E. Walsh

Westinghouse Savannah River Company

Savannah River Site

Aiken, SC 29808

An abstract of a paper proposed for presentation at the IPCC-1991 (International Professional Communications Conference) Orlando, Florida October 30-November 1, 1991

and for publication in the proceedings

\begin{abstract}
This report was prepared as an account of work sponsored by an agency of the United States Government. Neither the United States Government nor any agency thereof, nor any of their employees, makes any warranty, express or implied, or assumes any legal liability or responsibility for the accuracy, completeness, or usefulness of any information, apparatus, product, or process disclosed, or represents that its use would not infringe privately owned rights. Referenc. herein to any specific commercial product, process, or service by trade name, trademark, manufacturer, or otherwise does not necessarily constitute or imply its endorsement, recommendation, or favoring by the United States Government or any agency thereof. The views and opinions of authors expressed herein do not necessarily state or reflect those of the
United States Government or any agency thereof.
\end{abstract}

*The information contained in this article was developed during the course of work under Contract No. DE-AC09-89SR18035 with the U.S. Department of Energy. By acceptance of this paper, the publisher and/or recipient acknowledges the U.S. Government's right to retain a nonexclusive, royalty-free license in and to any copyright covering this paper along with the right to reproduce, and to authorize others to reproduce all or part of the copyrighted paper. 
WSRC-MS-91-276

\section{UPGRADE OF THE DEPARTMENT OF ENERGY'S SAVANNAH RIVER SITE'S REACTOR OPERATIONS AND MAINTENANCE PROCEDURES (U)}

by

T. E. Walsh

Westinghouse Savannah River Company Savannah River Site

Aiken, SC 29808

\section{ABSTRACT}

This paper describes the program in progress at the Savannah River Site (SRS) to upgrade the existing reactor operating and mainienance procedures to current commercial nuclear industry standards. In order to meet this goal, the following elements were established:

(1) administrative procedures to govern the upgrade process

(2) tracking system to provide status and accountability

(3) procedure writing guides

The goal is to establish a benchmark of excellence by which other Department of Energy (DOE) sites will measure themselves. The above three elements are addressed in detail in this paper.

\section{INTRODUCTION}

The Westinghouse Electric Corporation assumed the operation of the Department of Energy's SRS on April 1, 1989. The Reactor Training and Procedures Department (RTAP) is a part of the Westinghouse Savannah River Company's (WSRC) Reactor Restart Division. RTAP's charter is to provide to division personnel the necessary training and procedures to safely operate and maintain the reaciors.

*The information contained in this article was developed during the course of work under Contract No. DE-AC09-89SR18035 with the U.S. Department of Energy. 
The SRS occupies a 300-square-mile area in South Carolina, 25 miles southeast of Augusta, Georgia. The SRS produces nuclear materials, primarily plutonium and tritium for the DOE. The SRS facilities include: five production reactors - one operational, one standby, and three non-operational; two chemical separation facilities; a heavy water recovery plant; fuel fabrication facilities; waste processing facilities; the Savannah River Laboratory (SRL); Ecology Laboratory; and various administrative facilities. The production reactors were designed by E. I. DuPont de Nemours and Company (Du Pont) in the early 1950s.

\section{DISCUSSION}

\section{Initial Status Of The Procedures Program - April 1989}

The Reactor Restart Division's operating and maintenance procedures consisted of approximately 5300 procedures. Selected procedures were revised to meet an approved Reactor Operations Management Plan (ROMP). The ROMP is the WSRC restart plan, approved by the DOE. Administrative guidelines to control the procedure were not in place, and no method of tracking the procedure's paper flow was available. A computer network was available to store and retrieve the procedures for revision. When the procedure was sent out for local review by the applicable departments, the response time varied from a few weeks to months. With this lack of paperwork control, it was impossible to estimate how long it would take to complete a revision.

\section{Governing The Process With Administrative Procedures}

Over the last 12-18 months, administrative guidelines have been implemented to control each aspect of the procedure's development and revision. Specific aspects of the process that were addressed were review (verification), comment concurrence, walkdowr. (validation), and management approval. The following is a list of the current administrative guidelines that control the procedure:

(1) development and control of reactor operations, component handling, and maintenance procedures

(2) Operations and Maintenance Procedures Review and Approval Committee (OMPRAC)

(3) verification and validation

(4) periodic review of procedures

(5) technical procedures reviewer qualifications

(6) Walkdown Validator Qualification Program

Reviews are required by (for):

(1) A qualified reviewer in the applicable department with

(2) cross disciplinary review to include Reactor Engineering and Quality, where applicable by the technical specifications, and

(3) other affected departments 
Qualification requirements were established for the procedure validators who walk down the procedure for user and plant compatibility. Originally, the writer of the procedure had the authority to determine if a validator's comments should be incorporated into the procedure. In cases where the writer and the validator could not come io an agreement, the writer prevailed and the validator felt his efforts were wasted. Comment resolution by the writer, such as, "This concern should have been covered by the operator's or maintenance technician's training," was not acceptable to the validator, nor did it improve the procedure. The administrative guideline was revised to require the return of all comment dispositions to the reviewer for acceptance. In instances where acceptance is not given, and a compromise cannot be reached, the administrative guideline passes the issue to the Management Review Committee.

When all of the review comments are resolved, including those generated from the walkdown (if applicable), the procedure may take one of two paths:

(1) An administrative safety related, abnormal, or emergency procedure must receive a review by the Management Review Committee.

(2) All other types of procedures proceed directly to the responsible manager for signature. The responsible manager, such as the operations manager, the maintenance manager, or the charge and discharge manager, is the individual who is held responsible for this particular procedure.

\section{Tracking The Procedure Revision}

The Tracking and Interface (T \& I) Group was formed to ensure that the Procedures Group knew where each of its procedures was in the review process. Periodic status reports were provided to management to track and close findings by outside oversight groups, ROMP issues, and routine work items. Work process instructions (desk top instructions) were put in place to guide the clerical personnel and writers in their day-to-day activities. In order to positively control the flow of paperwork, a chain-of-custody transfer form was implemented. The individual or group receiving or transmitting the procedure must sign for it.

This information is entered into the Electronic Procedures System (EPS) for tracking. The software in the EPS has the ability to sort this data by procedure, by issue, by the writer, by the reviewer, by its status, by key words, or by several other variables. This information is available to the writers on the EPS network, and is provided to management and the review groups on a weekly basis. Data entry by the Procedure Group's clerks maintains the systems accuracy within 24 hours. The system could be a real-time system if each group that handles the procedure could be relied upon to religiously update the procedure's status. Unfortunately, experience has shown that all parties do not properly update a procedure's status.

The data base provides more than status reports of where procedures are in the process; it is used to calculate the time to process various procedures so that meaningful estimates of the time required to complete a number of procedures may be made. The data base is used to maximize the efforts of the procedure writers in completing ROMP issues, focus attention, and aid resource loading. For example, the ROMP issue may consist of one procedure or 400 . The trackers analyze data to determine procedures that are affected by common issues. Then, they screen to see which issue, if focused upon, will have the strongest impact on the completion of a second or third issue. This minimizes the chances of the writer having to revise a procedure for one issue, and at a later date, having to revise it for a second issue. This function allows the scheduler and the writer to be in the same office. 
Besides the review and approval process, various oversight groups review the procedures and publish their findings. These findings are assigned to the appropriate procedure manager for resolution. T\&I maintains a computer-based file to track the progress made toward the closure of each finding. T\&I is responsible for resolving the problems that occur as findings are reviewed. Generation of the closure reports that are sent to the oversight groups once the problems have been corrected is also a T\&I responsibility.

Courier service from the Procedures Group to the various reviewers, managers, and document control centers is provided. Too much time, as well as accountability, was lost by placing the procedure in the site mail system.

\section{Developing The Procedure Writer's Guides}

The guide that was available in late 1989 reflected the site's quality assurance manuals and included the commercial nuclear industry's minimum guidance documents. This guide has been used to revise the procedures for the ROMP issues.

New Writer's guides for developing procedures more in-line with the commercial nuclear industry have been created. These guides are based on those currently in use at a large U.S. utility that had undergone an extensive procedure upgrade program at the request of the U.S. Nuclear Regulatory Commission (USNRC). The utility's guides reflect the current thinking in the industry and address the appropriate human factors concerns from Nuclear Regulation (NUREG) and Institute of Nuclear Power Operations (INPO) documents.

The Procedure Group at the SRS took the existing guides (which were on a word processing system identical to the one used by the RTAP Procedures Group) and replaced the utility's examples with site-specific examples.

RTAP has decided to generate separate writers' guides for the operations and maintenance procedures. Though the majority of the information contained in the guides would be identical, it was felt that the guides would be better acceptance by the writers if each had his or her own distinct guide with common format and structure, but unique instructions pertinent to their specific procedures.

All maintenance procedures developed and reviewed after July 1, 1991, will be in compliance with the new writers' guide. The lead procedures are the maintenance procedures because only changes in format and human factors were made. The technical upgrade of the maintenance procedures was begun in February 1990 using the old writers' guide. The new guide will continue these technical upgrades, and will add format and human factors changes. On the other hand, the commercial-style operations procedures will require extensive training of operation prior to their implementation. This is due to the structure of the operations procedures in the new system. The current structure reflects two types of plant status - abnormal and normal. The procedures are categorized as those for abnormal condition control, and the remainder (which provide startup, operation, shutdown, and surveillance instructions). The new system will have the procedures split into the following groups:

(1) General operating procedures (GOPs) that provide structured steps for overall plant operation, and direct the performance of system operating procedures, surveillance procedures, and peri- odic procedures.

(2) System operating procedures (SOPs) that provide detailed steps for operating plant systems under normal operation, including placing systems in service and removing systems from service. 
(3) Surveillance procedures (SPs) that provide detailed steps to test technical specification equipment to ensure surveillance requirements are fulfilled, and that the equipment will be functional when it's needed.

(4) Periodic procedures (PPs) that provide detailed steps to test the non-technical specification equipment to ensure it remains operable and available.

(5) Annunciator response procedures (ARPs) that provide corrective actions to clear the alarm condition, or refer to other procedures, such as abnormal operating procedures and emergency operating procedures.

(6) Abnormal operating procedures (AOPs) that provide detailed steps during an abnormal plant condition that, if not corrected, could lead to an event or accident condition.

(7) Emergency operating procedures (EOPs), are event-based procedures that provide guidance during an accident if the event is known. The procedure deals specifically with actions used to respond to the specific event.

(8) Symptom based procedures (SBPs) provide guidance during an accident if the event is unknown, and the operator must rely on available symptoms to diagnose the situation, and determine the appropriate action to take to return the plant to a safe condition.

The number of procedures will be reduced from their current level of approximately 5300 to approximately 2300 . This reduction is the result of combining the many procedures the operator was referenced to by other procedures. In some instances, we will be able to replace 21 procedures with one new procedure. A system has been established to verify that all pertinent information from the existing procedures has been incorporated in the replacement procedure. With fewer proce.dures, greatly reduced referencing, and enhanced human factors, the number of operator errors attributable to procedures should decrease.

In summary, to have a viable procedure program, an organization must have the following elements in place:

(1) administrative procedures to control the complete process from the initial drafting of the procedure to the final approved version

(2) procedure writer's guides to ensure that all of the procedures are written in the same format and incorporate the appropriate human factors concerns

(3) a tracking system to provide management with accurate and timely information on the location of all procedures in the review cycle and the time that is required by the various groups to complete the tasks.

The procedures program is like a three-legged stool consisting of the administrative procedures, the Tracking and Interface Group, and the procedure writer's guides. If any of the legs are weak or missing, the stool will not provide the required support.

\section{ACKNOWLEDGEMENT}

The information contained in this article was developed during the course of work under Contract No. DE-AC09-89SR18035 with the U.S. Department of Energy. 

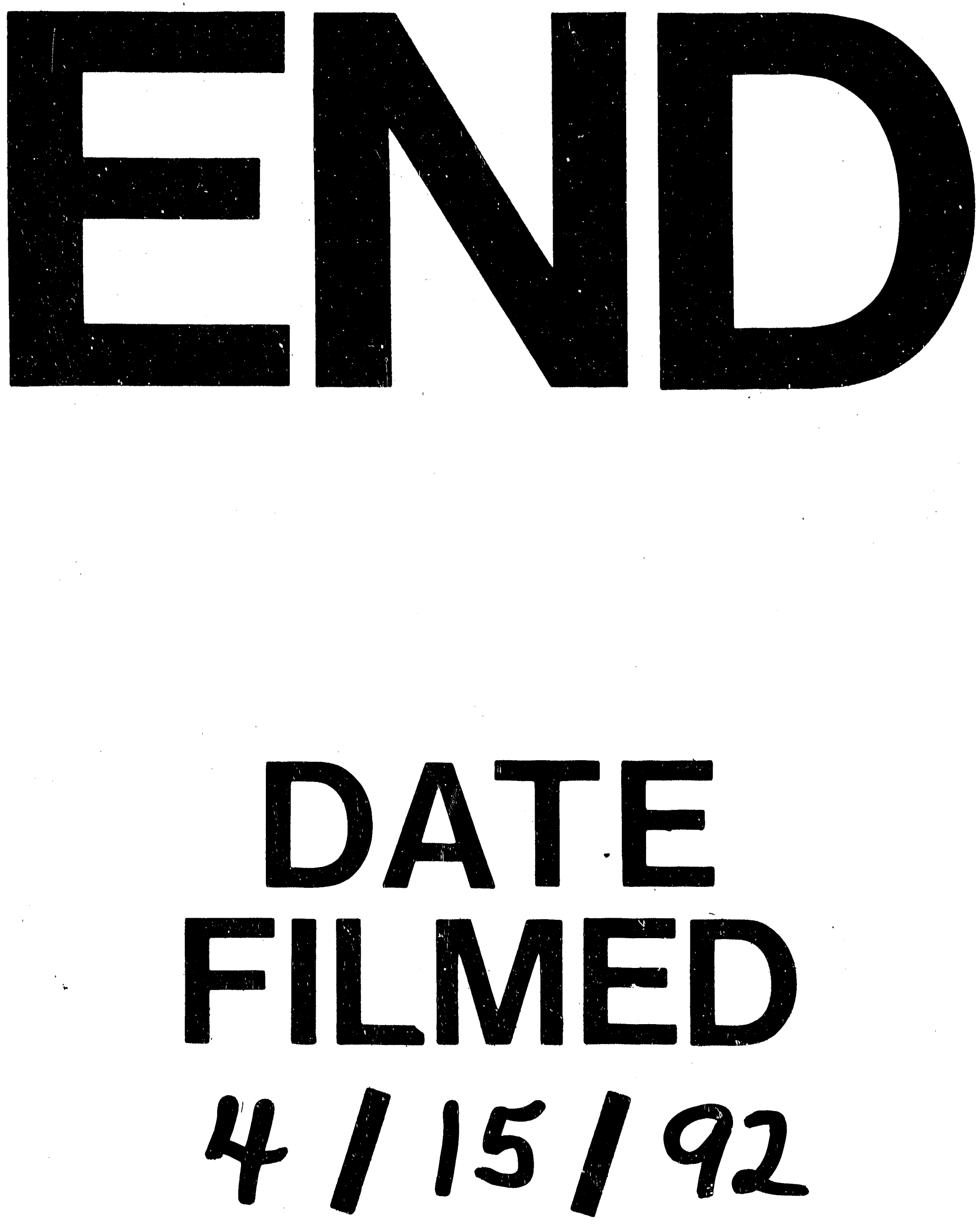
